SURVEY REPORT

\author{
Available Online at www.ijarcs.info
}

\title{
PERFORMANCE ANALYSIS OF ISM BAND ANTENNAS: A SURVEY
}

\author{
Neha Minhas \\ M.Tech Scolar \\ Electronics and Communication Engineering Department \\ Ambala College of Engineering and Applied Research, \\ Devsthali,Ambala, India
}

\author{
Ashok Kumar \\ Associate Professor and Head \\ Electronics and Communication Engineering Department \\ Ambala College of Engineering and Applied Research, \\ Devsthali,Ambala, India
}

\author{
Sarbjeet Singh \\ Assistant Professor \\ Electronics and Communication Engineering Department \\ Ambala College of Engineering and Applied Research, \\ Devsthali,Ambala, India
}

\begin{abstract}
Initially, ISM (Industrial, Scientific and Medical) band was being allocated to Industry, Science and Medical fields but later on various applications such as Wi-Fi, Bluetooth, cordless phone etc. have been allowed to use ISM band frequencies. Different types of antennas such as a microstrip patch antenna, helical antenna, dielectric resonator antenna etc are used for the above mentioned devices. However, due to small size and weight microstrip patch antenna become dominant in this field from last few years. In this paper various antenna designs for ISM band application have been discussed with their performance analyses from various papers on which this survey is conducted. The main aim of this survey paper is to provide a background on the researches of ISM band antenna design used for different application which would help researcher in their work.
\end{abstract}

Keywords: Industrial, scientific and medical(ISM) radio Band, performance analysis, microsrip patch antenna

\section{INTRODUCTION}

In the last few years there has been a significant development in antenna technologies in various fields such as Wi-Fi technology and wireless local area networks (WLAN) [1]. ISM band is a radio band which was reserved for industrial, scientific and medical purposes initially. However, in present Bluetooth devices, cordless phones, printer, keyboard, mouse, gaming controller applications and most of the wireless application are used in this band. Voice, video and data communications are also being used in $2.4 \mathrm{GHz}$ band which require higher data rates that are up to $300 \mathrm{Mbps}$. The $5 \mathrm{GHz}$ frequency ISM band is also adopted in commercial Wi-Fi applications. It is used as a backhaul link connecting two 2.4 $\mathrm{GHz}$ systems over some distance. Around $60 \mathrm{GHz}$ ISM band offers abundant bandwidth, enabling wireless communication with very high data throughput [2].

For the ISM band, various type of antenna designs are being used to cover this frequency band such as microstrip patch antenna, helical antenna, dipole antenna, dielectric resonator antenna, monopole antenna and planner antenna [3]. Various researches are done from several years to improve antenna performances in different aspects for different ISM band applications.

In this paper, several antennas along with microstrip patch antennas have been discussed. Patch antennas are more emphasize in this paper as compare to its counterparts due to several features such as relative wide impedance, easy impedance matching, small in size, good radiation efficiency, light weight, low fabrication cost [4].

The concept of microstrip radiator was first introduced by Deschamps in 1953 and in 1970s the first practical microstrip antenna was used [5]. Microstrip patch antenna is an antenna which is fabricated on a substrate using modern printed circuit board technology. The simplest configuration of a microstrip patch antenna consists of a radiating patch on the top side of a dielectric substrate which has a ground plate on the other side. Different feed techniques such as microstrip line, coaxial probe, aperture coupling and proximity coupling are used to excite the patch antenna. The shape of the patch may be designed in any form like rectangular, circular or triangular according to need for particular application.

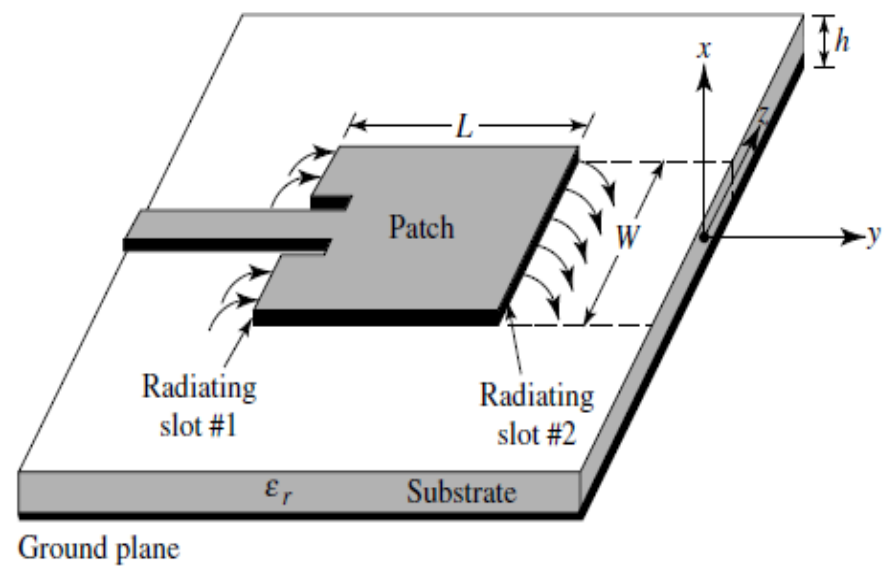

Figure 1. Pictorial view of Microstrip patch antenna[6] 


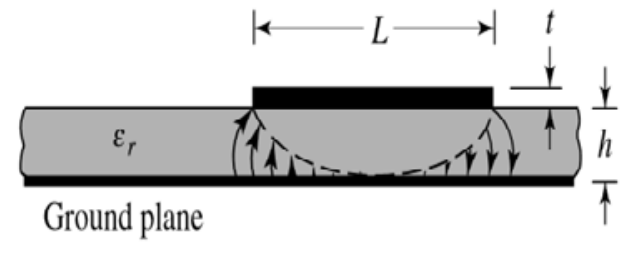

Figure 2. Side view of Microstrip patch antenna[6] power, unnecessary feed radiations. But lot of work is done to improve its performances such as stacking techniques, by the use of fractal geometries, metametrials, and Defective ground plane for particular applications. Stacking improve bandwidth in patch antennas. Multiband and Broadband characteristics can be achived by the use of fractal geometries. Metametrials as a substrate improves directivity, and defective ground plane act as notch filter for particular frequencies. For achieving desire characteristics several modifications were done in existing antenna structures some of which are being discussed in table 1.

However, Microstrip patch antennas have some disadvantages too such as low bandwidth, insufficient gain, low operating

Table I. Challenges in antenna design

\begin{tabular}{|c|c|c|c|}
\hline Sr No. & $\begin{array}{l}\text { Design } \\
\text { properties }\end{array}$ & $\begin{array}{l}\text { Related } \\
\text { work }\end{array}$ & Technique used in antenna design \\
\hline 1 & $\begin{array}{l}\text { Antenna } \\
\text { miniaturization }\end{array}$ & $\begin{array}{l}{[9],} \\
{[10],} \\
{[12]}\end{array}$ & $\begin{array}{l}\text { Complementary split ring resonator [9]. } \\
\text { Three layer open loops and printed on a substrate with high relative dielectric } \\
\text { constant [10]. } \\
\text { Square patch antenna with a center square slot [12]. }\end{array}$ \\
\hline 2 & Multiband & $\begin{array}{l}{[1],[3],} \\
{[14],} \\
{[17],} \\
{[18],} \\
{[19]}\end{array}$ & $\begin{array}{l}\text { Modified inverted- L antenna with ground stub [1]. } \\
\text { A printed monopole for WiFi and for WiGig channels high order mode patch antenna } \\
\text { [3]. } \\
\text { Two stacked concentric patches assembled by two orthogonally placed vertical } \\
\text { probes [14]. } \\
\text { A spiral element and a parasitically coupled monopole element [17]. } \\
\text { A segmented loop and a meander line structure [18]. }\end{array}$ \\
\hline 3 & Gain & [15] & $\begin{array}{l}\text { A stacked concentric patches assembled by two orthogonally placed vertical probes } \\
\text { [15]. }\end{array}$ \\
\hline 4 & $\begin{array}{l}\text { Bandwidth } \\
\text { enhancement }\end{array}$ & $\begin{array}{l}{[1],[7],} \\
{[16]}\end{array}$ & $\begin{array}{l}\text { Modified inverted-L antenna with a ground stub [1]. } \\
\text { The E shaped patch is selected [7]. } \\
\text { Printed monopole using ring shape ground[16] }\end{array}$ \\
\hline 5 & $\begin{array}{l}\text { Better return } \\
\text { loss }\end{array}$ & {$[8],[14]$} & $\begin{array}{l}\text { Genetic algorithm technique is used in IE3D software [8], } \\
\text { Two stacked concentric patches assembled by two orthogonally placed vertical probe } \\
\text { [14]. }\end{array}$ \\
\hline 6 & Low cost & {$[3],[7]$} & $\begin{array}{l}\text { PCB and plated through hole technology is used [3]. } \\
\text { Microstrip patch antenna [7] }\end{array}$ \\
\hline
\end{tabular}

This paper is organized in seven sections. In section II, describes the literature survey on the work done by various authors on different antenna for ISM band. Section III addresses the various gaps of the study. In section IV, Various parameters like gain, bandwidth, Return loss of antenna etc are discussed. The performance analysis based on survey is given in section V. In this comparison is made on the bases of their result. Sections VI conclude the survey and finally in section VII future scope are discussed.

\section{LITERATURE SURVEY}

The large numbers of researches have done on different antennas which operate in ISM band and some of them are mention here.

In 2012 Gye Taek Jeong et al. [1] presented a dual band modified inverted-L antenna with ground stub for $\mathrm{Wi}-\mathrm{Fi}$ applications which provides a wide bandwidth.

Julien Hautcoeur et al. [2] discussed an optically transparent planar monopole antenna for $60 \mathrm{GHz}$ ISM band application which shows similar result as of an identical antenna. It also use gold grid layer by which ohmic and skin depth losses become negligible.
Dian Wang et al. [3] presented a low cost PCB dual band antenna for future wireless local area network (WLAN) application. The antenna is based on a printed monopole to cover entire WiFi channels $(2.4 / 5.2 / 5.8 \mathrm{GHz})$ and for WiGig channels high order mode patch antenna is chosen.

Chien Jen Wang et al. [4] worked on a coplanar waveguide monopole antenna in which a rectangular monopole antenna and a feeding structure are fabricated on the same plane and a shorted inverted L strip is proposed which results in bandwidth enhancement.

Zhongkun Ma and Guy A. E. Vandenbosch et al. [7] introduced three novel two dimensional wideband microstrip.

Shruti Vashist et al. [8] introduced a genetic algorithm optimization technique in IE3D software to achieve better return loss, SWR and radiation properties for microstrip patch antenna to operate in ISM band at $2.4 \mathrm{GHz}$.

Mohammad S. Sharawi et al. [9] proposed a 2*2 MIMO patch antenna system it uses complementary split ring resonator (CSRR) on is ground plane for antenna miniaturization.

For antenna miniaturization Changrong Liu et al. [10] presented a microstrip patch antenna for $2.4 \mathrm{GHz}$ biomedical application. The proposed antenna consists of a square patch 
with a center square slot which also provides good polarization purity.

Henridass Arun et al. [11] proposed a design of microstrip +antenna arrays which has modified serpentine structure (MSS) for isolation enhancement to operate at $2.45 \mathrm{GHz}$ used for MIMO application.

Changrong Lui et al. [12] presented a miniaturized circularly polarized helical antenna for $2.4-2.48 \mathrm{GHz}$ ISM band

It was an ingestible capsule endoscope system which can be used for diagnostic and health treatment.

Chun-Cheng and Jwo-Shiun Sun [13] presented a cylindrical dielectric resonator antenna for $2.4 \mathrm{GHz}$ which provides good circularly polarization.

For high gain Qiang Liu et al. [14] introduced a dual band circular polarized microstrip patch antenna for radio-frequency identification (RFID) reader application. The antenna consists of a wideband dual-feed network and two stacked concentric patches assembled by two orthogonally placed vertical probes which also result in antenna miniaturization and retune loss grater then $10 \mathrm{db}$.

Anastasios Paraskevopoulos et al. [15] presented a flexible high-mode microstrip patch antenna (HMMPA) for on body communication. The embroidery technique used in it enabled a side fed low profile antenna which could be placed directly against the body. The proposed antenna can be easily installed in smart clothing and work together with on body communication devices. The antenna is also compared with HMMPA antenna with copper grid for both free space and on body condition.

R. Anitha et al. [16] introduced a compact quad element wideband antenna for MIMO application. This antenna provides bandwidth from 2.2 to $6.28 \mathrm{GHz}$ which covers LTE, Bluetooth, WLAN, WiMAX, ISM band (2.4/5.2/5.8).

J. L. Buckley et al. [17] introduced a compact dual ISM band antenna which uses spiral structure with parasitic element.

Parisa Forouzannezhad et al. [18] introduced a multiband compact RFID microstrip design for wireless application. It is shown that the proposed antenna structure provide strong near $\mathrm{E}$ and $\mathrm{H}$ field and provide good impedance matching for far field application.

Anitha Ramachandran et al. [19] proposed a compact multiband four port antenna which uses SRR ring for high isolation. The antenna resonate at three band $1.95-2.5 \mathrm{GHz}$ covering UMTS, LTE and 2.4-GHz ISM bands, 3.15-3.85 GHz covering WiMAX band, and 4.95-6.6 GHz covering 5.2/5.8GHz ISM bands.

Thus in literature studied so far, several methods are given to use same antenna for more than one frequency that is one antenna can be used as a dual band antenna or multiband antenna. Moreover special attention is given in the reduction of size of antenna, improving the bandwidth of antenna, reduction in mutual coupling and enhancing the efficiency of antenna. Antenna mentioned are also used for multiple input multiple output MIMO system as it offers increase in data throughput and link range without additional bandwidth or increased transmit power[11].

\section{A. Gaps in the Study}

- Designs of antenna should be modified to have wider frequency in single antenna for various applications.

- $\quad$ Microstrip patch antennas have better return loss and bandwidth applications, but still it has poor polarization purity, limited power capacity and efficiency.

- Antenna designs are complex.

- Size of antenna can be reducing without affecting its efficiency.
- $\quad$ Stacking of microstrip element and defected ground structures (DGS) can be use to improve the bandwidth of antenna.

\section{Parameters Of Antenna}

\section{A. Gain and Directivity}

The gain of an antenna is a parameter which is used to measure the degree of directivity of the radiation pattern of the antenna. It is actually the ratio of the radiation intensity in a given direction to the radiation intensity that would be obtained if the antenna delivered all of the power equally in all directions [6]. The definition of gain requires the concept of an isotropic radiator; that is, one that radiates the same power in all direction. An isotropic antenna is just a concept, for all practical antennas should have some direction properties. The gain of antenna is measured in decibels $(\mathrm{dB})$. For the gain of isotropic radiation measuring units are in $\mathrm{dBi}$ and for half wave dipole units are $\mathrm{dBd}$. Gain and directivity are the same with a difference. Directivity does not include the effect of power loss. When the antenna is lossless, then the gain and directivity are the same. Directivity of an antenna can also be measured from beamwidth.

\section{B. Beamwidth}

Beamwidth of a pattern is the angular separation between two identical points on opposite side of the maximum pattern. The widely used beamwidths is the half power beamwidth. It is considered is an important parameter of antenna as if the beamwidth decreases the side lobe increases and vice vesa [6].

\section{Radiation pattern}

An antenna radiation pattern is defined as a mathematical function or a graphical representation of the radiation properties of the antenna as the function of space coordinates [6]. These radiation properties include power flux density, directivity, field strength, phase or polarization. Various parts of radiation pattern are referred to as lobes. The radiation lobe which contains the direction of maximum radiation is known as the main lobe. The other lobes are called the side lobes and the lobes at the 180 degree of the main lobe called the back lobes as shown in fig below. For an isotropic antenna the radiation pattern is to be a sphere shape.

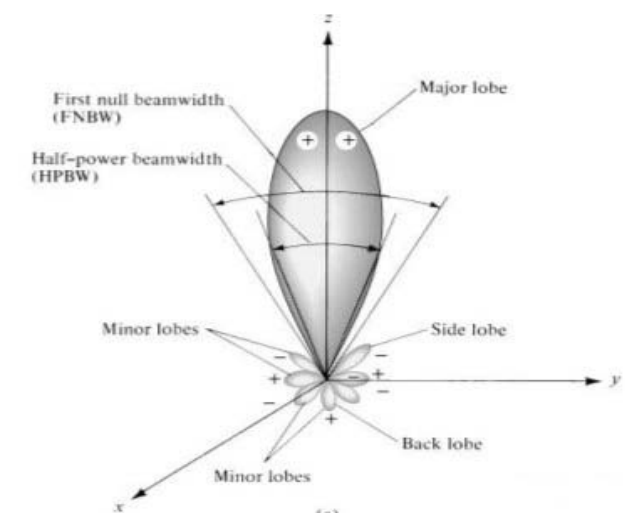

Figure 3. Major lobe, Minor lobe, Side lobe and Back lobes[6]

\section{Antenna Polarization}

The term polarization has several meaning, in a strict sense; it is the orientation of the electric field vector $E$ at some point in space. If the $\mathrm{E}$ - field vector retain its orientation at each point in space, then the polarization is circular or 
elliptical. In most cases, the radiated wave polarization is linear and either vertical or horizontal. At sufficiently large distances from an antenna, beyond 10 wavelengths, the radiated, far field is a plane wave.

\section{E. Return loss and VSWR}

It is a parameter which states the amount of power that is lost and does not return as a reflection. So the return loss is a parameter that specifies how good the matching between the transmitter and antenna has taken place. Mathematically it is defined by the ratio of the incident power of the antenna ' $\mathrm{P}_{\mathrm{i}}$ ' to the power reflected back by the antenna to the source ' $\mathrm{P}_{\mathrm{r}}$ ' as given by this equation.

$$
R L=10 \log _{10} \frac{P_{i}}{P_{r}}
$$

The ratio $\mathrm{P}_{\mathrm{i}} / \mathrm{P}_{\mathrm{r}}$ should be high for good power transfer. VSWR means Voltage Standing Wave Ratio is a function of the reflection coefficient, the smaller the value of the VSWR the better the antenna is matched to the transmission line.

\section{Performance Analysis Based On Survey}

The performance analysis has been done based on different parameter like gain, return loss and efficiency of antenna.

\section{A. Comparison of gain}

A comparison among the values of gain is being carried out for the different proposed antenna design by different researchers.

Table II. Comparison of bandwidth and gain

\begin{tabular}{|c|c|c|c|}
\hline Sr. No. & Antenna design & Gain in dBi & $\begin{array}{c}\text { Oprating } \\
\text { frequency in } \mathbf{G H z}\end{array}$ \\
\hline $\mathbf{1}$ & {$[1]$} & 2.28 & 2.45 \\
$\mathbf{2}$ & {$[2]$} & 3.2 & 56.1 \\
$\mathbf{3}$ & {$[4]$} & 3.4 & 2.6 \\
$\mathbf{4}$ & {$[8]$} & 5.65 & 2.4 \\
$\mathbf{5}$ & {$[13]$} & 2.7 & 2.4 \\
$\mathbf{6}$ & {$[14]$} & 8.9 & 2.48 \\
$\mathbf{7}$ & {$[16]$} & 2.75 & 2.4 \\
$\mathbf{8}$ & {$[18]$} & 2.5 & 2.4 \\
$\mathbf{9}$ & {$[19]$} & 2.5 & 2.5 \\
\hline
\end{tabular}

In most of the papers the gain value lies between 2 to $3.4 \mathrm{dbi}$ only some antenna provide gain more than 5dbi like [8] and[14].

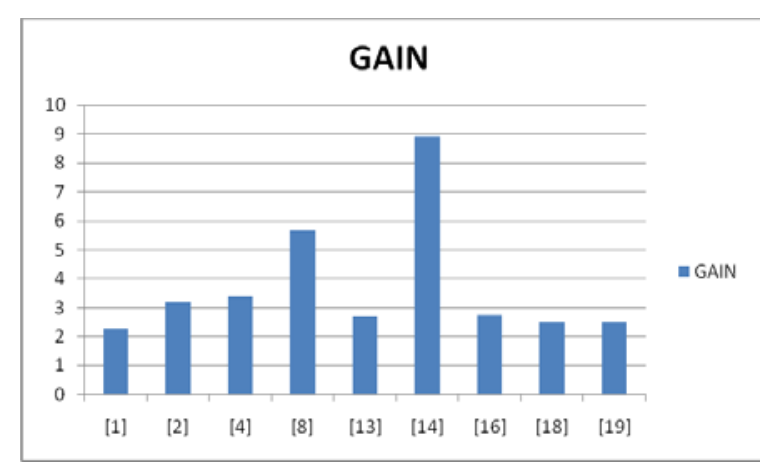

Figure 4. Example of a One-Column figure caption.

The above comparison graph shows that the gain of antenna design [14] is the largest which is 8.9dbi and antenna design [1] provides lowest gain among all.

\section{B. Comparison of return loss}

Return loss is the measure of the reflected energy from a transmitted signal. The grater the value, lesser is the energy reflected. The values of return loss are compared between antenna designs. The return loss is in $\mathrm{dB}$. The comparison table no. 3 is shown below.

Table III. Comparison of return loss

\begin{tabular}{|c|c|c|}
\hline Sr. No. & Antenna Design & Return Loss (dB) \\
\hline $\mathbf{1}$ & {$[8]$} & -28.5206 \\
$\mathbf{2}$ & {$[13]$} & -32 \\
$\mathbf{3}$ & {$[14]$} & -24 \\
\hline
\end{tabular}

The value of return loss is $-10 \mathrm{db}$ which is good enough in most practical cases. From the above graph it can be analyzed that antenna design [13] has return loss more than -30db which is the best from other two.

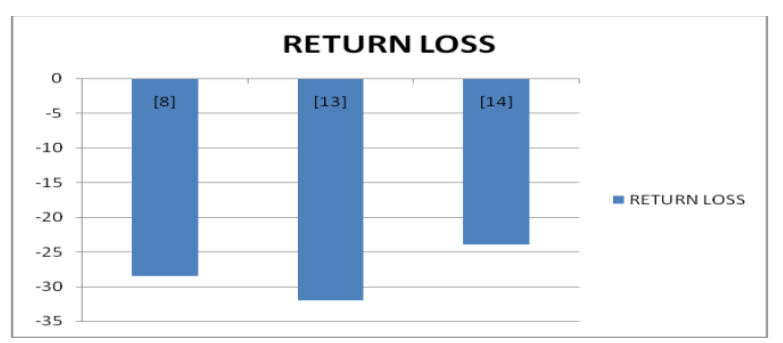

Figure 5. Example of a One-Column figure caption.

\section{Comparison of Antenna efficiency}

Efficiency of a transmitting antenna is mathematically given as the ratio of power radiated in all direction to the power absorbed by the antenna terminals. For good result the efficiency of antenna must be higher than $75 \%$ and in below table no.4 data shows that antenna design [15] has lower efficiency.

Table IV. Comparison of return loss

\begin{tabular}{|c|c|c|}
\hline Sr. No. & Antenna Design & Return Loss (dB) \\
\hline $\mathbf{1}$ & {$[8]$} & -28.5206 \\
$\mathbf{2}$ & {$[13]$} & -32 \\
$\mathbf{3}$ & {$[14]$} & -24 \\
\hline
\end{tabular}

The values of antenna efficiency are compared it is observed that the antenna design of [16] has a greater value and [15] has lowest value.

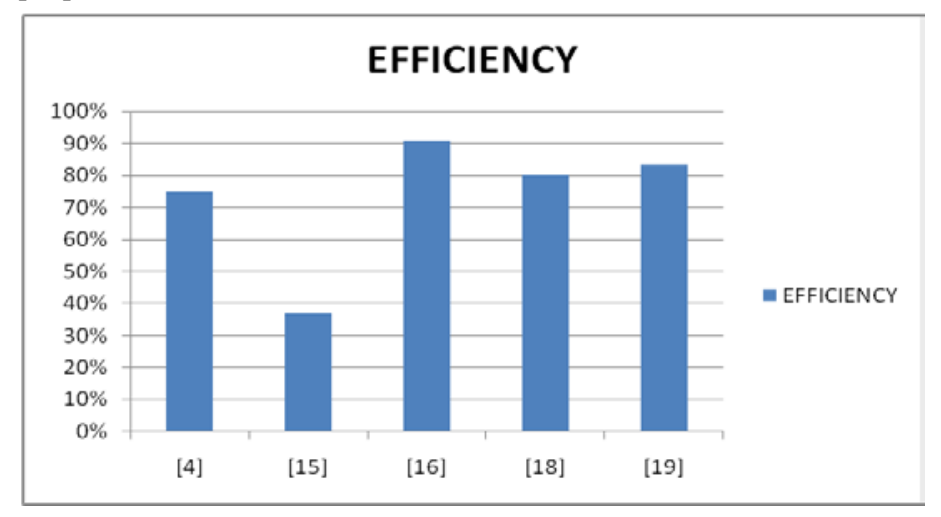

Figure 6. Comparison of efficiency of antenna 


\section{Conclusion And Future Scope}

In this paper, different design of ISM band antennas have been discussed and compared. The performance analyses from various papers have been done and there comparison is also shown by graphical representation. Gain, bandwidth and antenna efficiency are improved in the new ISM band antennas design as compared to conventional antennas. Bandwidth can be improved in microstrip patch antennas by using stacking and Defective ground structure (DGS). Miniaturizations in antennas are also results in reduction of overall system structure. Miniaturization can be done using fractal geometries.

In future, results can be improved by merging different techniques such as fractal geometers, Defective ground structure (DGS), metamaterials on a single antenna. Multiband properties can occur in microstrip patch antenna by using fractal geometries. To suppress undesire bands, defective ground structure (DGS) can be used as notch filter. On the same time, by using metamaterial, directivity of the same antenna can be improved.

\section{REFERENCES}

[1] Gye-Taek Jeong, Woo-Su Kim, Member, IEEE, and Kyung-Sup Kwak, Member, IEEE, 2012 "Dual-Band Wi-Fi Antenna with a Ground Stub for Bandwidth Enhancement” IEEE Antennas And Wireless Propagation Letters, Volume. 11.

[2] Julien Hautcoeur, Larbi Talbi, and Khelifa Hettak, Senior Member "Feasibility Study of Optically Transparent CPWFedMonopole Antenna at 60-GHz ISM Bands”, IEEE april 2013 IEEE transactions on antennas and propagation, vol. 61, no. 4, 1651

[3] Dian Wang, Student Member, IEEE, and Chi Hou Chan, Fellow, IEEE, 2016 "Multiband Antenna For Wifi And WigigCommunications" IEEE Antennas and Wireless Propagation Letters, Volume. 15.

[4] Chien-Jen Wang And Kai-Lung Hsiao February 2014 "CPWfed Monopole Antenna For Multiple System Integration” IEEE Transactions On Antennas And Propagation, Volume. 62, No. 2.

[5] Garg R.Bhartia P. and Ittipiboon A., 2001.”Microstrip Antenna Design Handbook Bostan Artech, House” pp 1-2.

[6] Balanis C. A., 2005 “Antenna Theory Analysis \& Design”, Edition $3^{\text {rd }}$, John Wiley \& Sons, Inc, Hoboken, New Jersey.

[7] Zhongkun Ma and Guy A. E. Vandenbosch JUNE 2012 "LowCost Wideband Microstrip Arrays With High Aperture Efficiency" IEEE transactions on antennas and propagation, vol. 60, no. 6.

[8] Shruti Vashist, M.K Soni, P.K.Singhal July 2013 "Genetic Approach in Patch Antenna Design” International Journal of Emerging Science and Engineering (IJESE) ISSN: 2319-6378, Volume-1, Issue-9, 70.
[9] Mohammad S. Sharawi, Senior Member, IEEE, Muhammad U. Khan, Student Member, IEEE Ahmad B. Numan, And Daniel N. Aloi, Senior Member, IEEE, February 2014 "A CSRR Loaded MIMO Antenna System For ISM Band Operation” IEEE Transactions on Antennas And Propagation, Volume. 61, No. 8.

[10] Changrong Liu, Student Member, IEEE, Yong-Xin Guo, Senior Member, IEEE, and Shaoqiu Xiao, Member IEEE, December 2014 "Circularly Polarized Helical Antenna for ISM-Band Ingestible Capsule Endoscope Systems" Transactions on Antennas and Propagation, Volume. 62, No. 12.

[11] Henridass Arun, Aswathy K. Sarma, Malathi Kanagasabai, Member, IEEE, Sangeetha Velan, Chinnambeti Raviteja, and M. Gulam Nabi Alsath February17,2014 "Deployment of Modied Serpentine Structure for Mutual Coupling Reductionin MIMO Antennas” IEEE antennas and wireless propagation.

[12] Changrong Liu, Student Member, IEEE, Yong-Xin Guo, Senior Member, IEEE, and Shaoqiu Xiao, Member IEEE, December 2014 "Capacitively Loaded Circularly Polarized Implantable Patch Antenna For ISM Band Biomedical Applications” IEEE Transactions on Antennas and Propagation, Volume. 62, No.5.

[13] Chun-Cheng Lin And Jwo-Shiun Sun, 2015 "Circularly Polarized Dielectric Resonator Antenna Fed By Off-Centered Microstrip Line For 2.4-Ghz ISM Band Applications” IEEE Antennas And Wireless Propagation Letters, Volume. 14.

[14] Qiang Liu, Junyu Shen, Jungang Yin, Member, IEEE, Hongli Liu, and Yuanan Liu, Member, IEEE, September 2015 "Compact $0.92 / 2.45-\mathrm{GHz}$ Dual-Band Directional Circularly Polarized Microstrip Antenna for Handheld RFID Reader Applications” IEEE Transactions On Antennas And Propagation, Vol. 63, No. 9.

[15] Anastasios Paraskevopoulos, D. de S. Fonseca, Rob D. Seager, W. G. Whittow J. C. Vardaxoglou and A. A. Alexandridis ,IEEE, February 2016 "Higher-mode texile patch antenna with embroidered vias on-body communication” IET Microwaves, Antennas \& Propagation, 2016, Vol 10, Iss.7 pp. 802-809.

[16] R. Anitha, P. V. Vinesh, K. C. Prakash, P. Mohanan, and K. Vasudevan. October 2016 "A Compact Quad Element Slotted Ground Wideband Antenna for MIMO Applications” IEEE Transactions on Antennas and Propagation, Volume 64, No. 10.

[17] J. L. Buckley, Member, IEEE, K. G. Mccarthy, Member, IEEE, L. Loizou, Member, IEEE, B. O’flynn, Member, IEEE, And C. O'mathuna, Fellow, IEEE 2016 "A Dual-Ism-Band Antenna Of Small Size Using A Spiral Structure With Parasitic Element" IEEE Antennas And Wireless Propagation Letters, Volume. 15.

[18] Parisa Forouzannezhad , Amir Jafargholi , Alireza Jahanbakhshi IEEE 2017"Multiband compact antenna for near-field and farfield RFID and wireless portable applications” IET Microwaves, Antennas \& Propagation Volume: 11, Issue: 4, 3182017 pp 535-541.

[19] Anitha Ramachandran, Sumitha Mathew, Vivek Rajan, and Vasudevan Kesavath, Senior Member, IEEE 2017 “A Compact Triband Quad-Element MIMO Antenna Using SRR Ring for High Isolation" IEEE Antennas And Wireless Propagation Letters, Vol. 16, 2017. 